\title{
Intraoperative allergic reactions to hydroxyethyl starch: a report of two cases
}

The presentation, evolution, and treatment of two cases of intraoperative allergic reactions are described. In each case, the offending agent was felt to be hydroxyethyl starch (HES), a synthetic polymer colloid solution used for intravascular volume expansion. Symptoms included urticaria, angioedema, and hypotension in the first patient, and urticaria, hypoxia, and haemoconcentration in the second patient. Both patients had earlier received multiple drugs andlor blood products. However, HES administration in both patients immediately produced allergic symptomatology. The first patient had concurrent depression of serum total complement levels (CH50) and no elevation of plasma histamine levels, which suggested a complement-mediated reaction to HES. Levels of CH5O and histamine were not obtained from the second patient. Direct stimulation of mast cell degranulation by the offending agent, complement activasion, or conventional antigen-antibody interaction in a previously exposed patient may initiate intraoperative allergic reactions. Anaesthesia personnel should be aware of the risk of intraoperative allergic reactions to $H E S$ and be prepared to treat them rapidly and effectivety.

Key words

COMPLICATIONS: allergic reaction; FLUID BALANCE: hydroxyethyl starch.

From the University of Kansas Medical Center, Department of Anaesthesiology.

Address correspondence to: Dr. Susan S. Porter, Department of Anesthesiology, Univcrsity of Kansas Medical Center, 39th and Rainbow Boulevard, Kansas City, Kansas 66103.
Hydroxyethyl starch (Hetastarch; HES) is a synthetic polymer colloid solution which has been demonstrated to be as effective as five per cent albumin as a plasma expander. ${ }^{\prime}$ It is also significantly less expensive, carries no risk of hepatitis, and does not interfere with subsequent blood typing. Dilutional thrombocytopenia and minor transient effects on clotting factors have been reported in vitro, ${ }^{2}$ but these effects have not been demonstrated to be associated with clinical evidence of bleeding. ${ }^{3}$ Anaphylactic reactions are mediated by antigen-antibody interactions in subjects previously exposed to the offending agent. Anaphylactoid reactions are often clinically indistinguishable, but are felt to be due to a direct effect of the drug on mast cells and basophils, resulting in histamine release. ${ }^{4}$ Although HES is non-antigenic there are scattered reports of allergic reactions following its use. ${ }^{5,6}$ There are no reports of allergic reactions during intraoperative administration, where the use of HES and other synthetic colloids is increasingly prevalent. An isolated prospective study found the incidence of severe anaphylactoid reactions following HES to be 0.006 per cent. ${ }^{7}$ We report the occurrence of two such probable reactions.

\section{Report of two cases}

Case 1

The patient was a 14-year-old, $37 \mathrm{~kg}$ male with spina bifida cystica and hydromyelia, scheduled for cervical exploration and posterior fossa decompression for progressive upper extremity weakness. He had previously undergone repair of a myelomeningocoele at $\mathrm{L}_{4}-\mathrm{L}_{5}$, ventriculoperitoneal shunt placement, numerous orthopedic procedures, and multiple shunt revisions, all performed under general anaesthesia without difficulty. $\mathrm{He}$ had no known 
allergies, and was taking no medications. He was premedicated with morphine $4 \mathrm{mg}$ intramuscularly and pentobarbitone $150 \mathrm{mg}$ by mouth two hours prior to induction.

On arrival in the operating room, the patient was sleepy and cooperative. Initial monitoring revealed blood pressure $13.3 / 8.0 \mathrm{kPa}(100 / 60 \mathrm{mmHg})$ by cuff, with a heart rate of $100 \mathrm{bpm}$. Anaesthesia was induced with halothane, 60 per cent $\mathrm{N}_{2} \mathrm{O}$ and 40 per cent $\mathrm{O}_{2}$ per facemask. An intravenous catheter was placed and infusion of lactated Ringer's solution begun. The patient was intubated without difficulty after receiving pancuronium $5 \mathrm{mg}$, lidocaine $50 \mathrm{mg}$, and fentanyl $400 \mu \mathrm{g}$. A peripheral central venous catheter and a percutaneous radial artery catheter were inserted. Blood pressure remained at $10.7-$ $12.0 / 6.7-8.0 \mathrm{kPa}(80-90 / 50-60 \mathrm{mmHg})$ and heart rate at $95-100 \mathrm{bpm}$. Central venous pressure was $0.27 \mathrm{kPa}(2 \mathrm{mmHg})$. Hydroxyethyl starch infusion was initiated for volume expansion prior to positioning. The patient was tumed prone, and a diffuse maculopapular rash was noted over the posterior trunk. Closer inspection revealed the rash to be generalized. Blood pressure fell to $8.0 / 4.0 \mathrm{kPa}$ $(60 / 30 \mathrm{mmHg})$, and heart rate increased to 100 bpm. No wheezing was heard over the lung fields, and pulmonary inspiratory pressures were unchanged. The HES infusion ( $300 \mathrm{ml}$ given) was immediately stopped, and the patient was treated with 100 per cent oxygen, dexamethasone $6 \mathrm{mg}$, ephendrine $5 \mathrm{mg}$, and intravenous lactated Ringer's solution. He was returned to the supine position and at that time generalized oedema of the face, lips, tongue, and oropharynx were noted. Blood pressure was $13.3 / 8.0 \mathrm{kPa}(100 / 60 \mathrm{mmHg})$ at this time and did not require further treatment.

The procedure was cancelled and the patient taken to the recovery room, where mechanical ventilation was continued and he was treated with hydrocortisone $100 \mathrm{mg}$, cimetidine $300 \mathrm{mg}$, and diphenhydramine $25 \mathrm{mg}$. He awoke rapidly and was then sedated with diazepam $5 \mathrm{mg}$ to facilitate continuing intubation. Arterial blood gases at this time revealed $\mathrm{pH} 7.45, \mathrm{PaO}_{2} 41.9 \mathrm{kPa}$ (314 torr), $\mathrm{PaCO}_{2} 4.0 \mathrm{kPa}$ (30 torr). A chest radiograph was normal. Over the next several hours, the patient's oedema and rash resolved, and he was extubated approximately ten hours later without difficulty. Serum total complement ( $\mathrm{CH50}$ ), drawn during the initial reaction, was depressed at 106 haemolytic units (normal range 130-230). Serum C3 was $88 \mathrm{mg} \cdot \mathrm{dl}^{-1}$ (normal range, 90-230) and $\mathrm{C} 4$ was $8 \mathrm{mg} \cdot \mathrm{dl}^{-1}$ (normal range, 7.2-15.8). Plasma histamine, also drawn at the time of the reaction, was within the normal range at $<1.0 \mathrm{ng} \cdot \mathrm{ml}^{-1}$. One month later, serum $\mathrm{CH} 50$ had returned to normal levels at 131 haemolytic units. Skin-testing at this time for evidence of immediate-type hypersensitivity reactions was negative for lidocaine and methylparaben. Unfortunately, neither HES nor the other drugs he received were tested.

\section{Case 2}

The patient was a 67 -year-old male scheduled for left ventricular aneurysm resection, coronary artery bypass grafting (CABG), and right carotid endarterectomy. The patient reported prior "allergies" to hydrochlorothiazide/triamterene (nausea) and diazepam (dizziness). Medical therapy included propranolol, chlorthalidone, nifedipine, nitroglycerine paste, and potassium supplementation.

After premedication with lorazepam, nifedipine, and propranolol, anaesthesia was induced with fentanyl $3500 \mu \mathrm{g}$, and pancuronium $10 \mathrm{mg}$ was administered to facilitate intubation. Prior to institution of cardiopulmonary bypass, the patient required intermittent doses of neosynephrine to maintain blood pressure, and had also received oxacillin 2 grams, gentamycin $80 \mathrm{mg}$, and heparin 7500 units. Carotid endarterectomy, aneurysm resection, and $C A B G$ proceeded uneventfully, and the patient was weaned from cardiopulmonary bypass with the aid of calcium chloride, nitroglycerine, sodium nitroprusside, and lidocaine. Protamine was given to reverse heparinization, with no signs of allergic reaction. Arterial blood gases at this time revealed pH 7.40, $\mathrm{PaO}_{2} 42.8 \mathrm{kPa}$ (321 torr), and $\mathrm{PaCO}_{2}$ $5.3 \mathrm{kPa}$ (40 torr). Haematocrit was 34 per cent. Hetastarch $500 \mathrm{ml}$ was infused during sternal closure for intravascular volume expansion. Within five minutes a diffuse urticarial rash develped, but no evidence of brochospasm, hypotension, arrhythmia, cyanosis, or oedema was noted at that time. On arrival in the intensive care unit, the patient's vital signs were: blood pressure $18.7 / 10.7 \mathrm{kPa}$ (140/80 $\mathrm{mmHg}$ ), heart rate 60 , and cardiac output 5.0 $\mathrm{L} \cdot \mathrm{min}^{-1}$. Initial arterial blood gases revealed $\mathrm{pH}$ 7.31, $\mathrm{PaO}_{2} 6.4 \mathrm{kPa}$ (48 torr), $\mathrm{PaCO}_{2} 6.0 \mathrm{kPa}$ (45 torr) on 100 per cent oxygen. Haematocrit was 47 per cent. The endotracheal tube was in proper 
position, and lungs were clear to auscultation. A chest radiograph showed no evidence of pneumothorax, infiltrate, pulmonary oedema, or other abnormality. The rash was still present. The patient received diphenhydramine $25 \mathrm{mg}$, hydrocortisone $300 \mathrm{mg}$, cimetidine $300 \mathrm{mg}$, and $15 \mathrm{cmH}_{2} \mathrm{O}$ PEEP was added to the respiratory circuit. This increased $\mathrm{PaO}_{2}$ to $14.4 \mathrm{kPa}$ (108 torr) on 100 per cent oxygen, and did not produce any haemodynamic compromise. Over the next 36 hours the patient's arterial oxygenation continued to improve, he was extubated and went on to recover without sequelae. Serum histamine and complement levels were not obtained.

\section{Discussion}

Hetastarch (HES) is a hydroxyethyl-substituted branched polymer of glucose structurally similar to glycogen. It is marketed as a six per cent solution in normal saline, with a $\mathrm{pH}$ of 5.5 , an osmolarity of $310 \mathrm{mOsm} \cdot \mathrm{L}^{-1}$, and a colloid osmotic pressure of $30 \mathrm{mmHg}$. HES solution is actually a heterogeneous mixture of polymers differing in size, chain length, and molecular weight. The average molecular weight is about $450,000 \mathrm{~g} \cdot \mathrm{mole}^{-1}$. Metabolism by alpha amylase produces smaller HES molecules of about $50,000 \mathrm{mw}$ which are excreted both by the kidney and via the biliary tract.

The distribution of a single dose of HES is dependent on the size of the molecules. Larger molecules are distributed throughout the plasma volume and into body tissues such as liver, spleen, kidney, heart, and lung. ${ }^{8}$ Smaller molecules are excreted unchanged. The pharmacologic effect and duration of action are therefore dependent on the relative proportion of small and large molecules. This heterogeneity also accounts for the persistence of HES for weeks to months, as molecules are mobilized from tissue depots. In normal subjects, plama volume expansion of HES appears to be effective for approximately 48 hours, and the serum half-life is slightly over two weeks. ${ }^{9,10}$

HES is indicated for use as a plasma volume expander in patients suffering from hypovolemic states. ${ }^{10,11}$ It has also been used as a pump-priming solution during cardiopulmonary bypass, for fluid resuscitation in postoperative cardiac surgical patients, ${ }^{3,12}$ and as an adjunctive sedimentary agent in donors undergoing leukapheresis. ${ }^{13}$

Complications of HES administration include circulatory overload and some suggestion of dilutional thrombocytopenia in doses greater than 25 per cent of estimated blood volume. ${ }^{3}$ Clinically, this antithrombotic effect has not been well demonstrated, but doses of greater than $1500 \mathrm{ml} \cdot \mathrm{day}^{-1}$ or $20 \mathrm{ml} \cdot \mathrm{kg}^{-1} \cdot \mathrm{day}^{-1}$ are not recommended. HES is normally well-tolerated; however, there are isolated reports of allergic reactions. In 1977, Ring and Messmer ${ }^{7}$ prospectively investigated the frequency of anaphylactoid reactions to colloid substances and found the incidence to be 0.014 per cent for plasma protein solutions, 0.032 per cent for dextran solutions, 0.115 per cent with gelatin preparations, and 0.85 per cent with HES. These included all types of reactions, varying in severity from minor to lethal. The incidence of severe reactions was highest for gelatin preparations ( 0.038 per cent), about equal for both dextran ( 0.008 per cent) and HES $(0.006$ per cent), and lowest for plasma protein solutions $(0.003$ per cent $)$.

Allergic reactions may manifest in the awake patient with symptoms of nausea, shortness of breath, itching, or dizziness. Signs may range from mild fever and skin erythema to bronchospasm, tachycardia, hypotension, angioedema of the face and airway, and cardiac or respiratory arrest. In severe cases, these manifestations are accompanied by hypoxia, cyanosis, acidosis, and haemoconcentration. Many of these features may be masked in the anaesthetized patient unless the reaction is very severe.

There are four mechanisms that can be responsible for allergic reactions after administrtion of a drug or other intravenous substance. All culminate in the production of chemical mediators which produce the pharmacologic effects and clinical symptoms of an allergic reaction. The first, anaphylaxis, is mediated by antigen interaction with antibodies present on mast cells, formed in response to previous exposure to the substance. Often this involves the drug or its degradation product binding to protein to form a complete antigen.

Activation of the complement pathway by a drug or intravenous substance can proceed either through interaction of the drug with IgG or IgM antibodies (the classical pathway) or by direct interaction of the drug with complement protein $\mathrm{C} 3$ (the alternate pathway). Complement activation ultimately results in mast cell degranulation. The fourth allergic mechanism can be designated as anaphylactoid, and 
is mediated by direct effects of drugs, often basic molecules, on mast cells. The manifestations of an anaphylactoid reaction are identical to those of anaphylaxis or complement activation, and no prior exposure to the substance is necessary. ${ }^{4}$

Hydroxyethyl starch has been demonstrated to be non-immunogenic in several species, including man. ${ }^{14,15}$ Lorenz et al. ${ }^{16}$ have shown that HES does not provoke histamine release. Since HES is metabolized to molecules of varying size, there is speculation that large molecular-weight particles could lead to complement activation via the alternate pathway. ${ }^{6}$ This has been described after exposure to dextran sulfate and gamma globulin aggregates. ${ }^{17-19}$

Our first patient exhibited stigmata of a moderately severe allergic reaction, including hypotension, urticaria, and angioedema. The depressed level of $\mathrm{CH} 50$ (which had returned to normal one month later) and the absence of elevated plasma histamine suggest that this reaction was mediated by complement activation with generation of a vasoactive peptide rather than histamine release initiated by the agent or by antigen-antibody interactions.

The second patient manifested urticaria, hypoxia for which there was no alternative explanation, and haemoconcentration. Since histamine and complement levels were not obtained, the mechanism of this reaction is unclear. An allergic response to HES in a previously-exposed patient has been reported, ${ }^{6}$ perhaps mediated by conventional antigen-antibody interactions. Whether our second patient had been previously exposed to HES is not known.

Both patients had received multiple drugs, and the second patient had also received blood products. However, neither patient had received any drug to which he had not previously been exposed or any blood product for 30 minutes prior to HES administration. Allergic manifestations appeared in both patients within five minutes of HES infusion. This does not rule out another substance as the responsible agent, but strongly implicates HES as the most likely offender.

Such reactions cannot be predicted, and a severe episode can be fatal. Therefore, we believe it is prudent to infuse HES, if possible, at a time when signs of an allergic reaction under anaesthesia are not likely to be misinterpreted as effects of other drugs or procedures. Since patients with strong allergic history may be at slightly higher risk, ${ }^{6}$ administration of a test dose $(20-30 \mathrm{ml})$ in these cases may be wise. In patients with a questionable history of previous reaction to HES, serum can be incubated with Hetastarch and observed for evidence of complement activation. ${ }^{19}$ Patient leukocytes can also be incubated with HES and observed for histamine release. ${ }^{4}$ Treatment of allergic reactions is largely supportive following discontinuation of the offending agent. In severe cases corticosteroids, antihistamines, bronchodilators, ventilatory support, and treatment of hypotension with intravenous fluids or vasopressors may be needed.

The occurrence of intraoperative allergic reactions of moderate severity in two patients at our institution within a short period of time attracted our notice and led us to examine the risk of producing similar reactions in the future. With the advent of multiple synthetic colloid solutions now offered as alternate plasma expanders to albumin, the likelihood of intraoperative allergic reactions increases. Anaesthesia personnel should be made aware of this risk and its pathogenesis, and be prepared to administer appropriate treatment rapidly and effectively.

\section{References}

1 Puri VK, Howard M, Paidipaty BB, Singh S. Resuscitation in hypovolemia and shock: a prospective study of hydroxyethyl starch and albumin. Crit Care Med 1983; 11: 518-23.

2 Strauss $R G$. Review of the effects of hydroxyethyl starch on the blood coagulation system. Transfusion 1981; 21: 299-302.

3 Diehl JT, Lester JL, Cosgrove DM. Clinical comparison of hetastarch and albumin in postoperative cardiac patients. Ann Thor Surg 1982; 34: 674-9.

4 Stoelting $R K$. Allergic reactions during anaesthesia. Anesth Analg 1983; 62; 341-56.

5 Ring $J$, Seifert $J$, Messmer $K$, Brendel $W$. Anaphylactoid reactions due to hydroxyethyl starch infusion. Eur Surg Res 1976; 8: 389-99.

6 Dutcher JP, Aisner J. Hogge DE, Schiffer CA. Donor reaction to hydroxyethyl starch during granulocytapheresis. Transfusion 1984; 24: 66-7.

7 Ring $J$, Messmer $K$. Incidence and severity of anaphylactoid reactions to colloid volume substitutes. Lancet 1977; 1: 466-9.

8 Thompson WL, Fukushima T, Rutherford RB, Walton $R P$. Intravascular persistence, tissue storage, 
and excretion of hydroxyethyl starch. Surg Gynecol Obstet 1970; 131: 965-72.

9 Yacobi A, Stoll RG, Sum CY, Lai CM, Gupta SD, Hulse JD. Pharmacokinetics of hydroxyethyl starch in normal subjects. J Clin Pharmacol 1982; 22: 20612.

10 Mishler J, Barberg H, Emerson PM, Gross $R$, Hydroxyethyl starch: an agent for hypovolemic shock treatment. J Surg Res 1977; 23: 239-45.

11 Lazrove S, Waxman K, Shippy C, Shoemaker WC. Hemodynamic, blood volume, and oxygen transport responses to albumin and hydroxyethyl starch infusions in critically ill postoperative patients. Crit care Med 1980; 5: 302-6.

12 Lell WA, Kirklin JK, Tosone SR, Dole K, Wright $D T$. Hydroxyethyl starch vs albumin for colloid infusion after $\mathrm{CPB}$ in patients undergoing $\mathrm{CABG}$. Anesthesiology 1982; 57: A113.

13 Huestis DW, White FR, Price MJ, Inman M. Use of hydroxyethyl starch to improve granulocyte collection in the Latham blood processor. Transfusion 1975; 15: 559-64.

14 Maurer PH, Berardinelli $B$. Immunologic studies with hydroxyethyl starch (HES) - a proposed plasma expander. Transfusion 1968; 8: 265-8.

15 Brickman RD, Murray GF, Thompson WL, Ballinger WF. The antigenicity of hydroxyethyl starch in humans: studies in seven normal volunteers. JAMA 1966; 198: 1277-9.

16 Lorenz W, Doenicke A, Freund $M$ et al. Plasma histamine levels in man following infusion of hydroxyethyl starch: a contribution to the question of allergic or anaphylactoid reactions following administration of a new plasma substitute. Anaesthetist 1974; 24: 228-30.

17 Konig W, Bitter-Suermann D, Dierich M, Hadding $U$. Bypass-activation of the complement system starting with C3. Immunochem 1973; 10: 431-7.

18 Mueller-Eberhard HJ, Gotze O.C3 proactivator convertase and its mode of action. J Exp Med 1972; 135: 1003-8.

19 Fudenberg $H H$, Stites DP, Caldwell $J L$, Wells $J V$. Basic and Clinical Immunology. Los Altos, Ca: Lange Medical publications, 1978: 72-4.

\section{Résumé}

La présentation, évolution et traitement de deux cas de réactions allergiques per-opératoires est décrite. Dans les deux cas, l'agent causal suggéré était l'hydroxyethyl starch(HES); une solution colloide de polymer synthétique utilisée pour l' expansion volémique. Les symptomes incluent l'urticaire, l'angioedènte et l'hypotension pour le premier patient et l' urticaire, hypoxie et hémoconcentration pour le second patient. Les deux patients avaient reçu au préalable de multiples médicaments etlou des produits du sang. Cependant, l'administration de HES aux deux patients a produit une réaction allergique immédiate. Le premier patient avait montré une dépression du niveau sérique de complément total (CH5O) et aucune élévation des niveaux d'histamine plasmatique, suggérant ainsi une réaction déclenchée par le complément. Les niveaux de CHSO et d'histamine n'éraient pas obtenus pour le deuxieme patient. Une stimulation directe aboutissant à la dégranulation des mastocites par l'agent causal, l'activation du complément, ou une interaction conventionnelle entre antigène-anticorps chez un sujet exposé au préalable peut initier une réaction allergique per-opératoire. Le personnel anesthésique doit être aux aguets des risques allergiques per-opératoires lors de l'administration du HES et être prêparé à les traiter rapidement et efficacement. 